\title{
Development of a Magnetic-Geared Permanent-Magnet Brushless Motor
}

\author{
L. L. Wang ${ }^{1}$, J. X. Shen ${ }^{1}$, P. C. K. Luk ${ }^{2}$, W. Z. Fei ${ }^{2}$, C. F. Wang ${ }^{1}$, and H. Hao ${ }^{1}$ \\ ${ }^{1}$ College of Electrical Engineering, Zhejiang University, Hangzhou, Zhejiang 310027, China \\ ${ }^{2}$ Department of Engineering Systems and Management, Cranfield University, Shrivenham, Wiltshire SN6 8LA, U.K.
}

\begin{abstract}
High-torque and low-speed electrical drives are often employed for applications where mechanical gearing cannot be accommodated. On the other hand, permanent-magnet (PM) gear has drawn significant attention from both academies and industries due to the conspicuous merits, such as reduced acoustic noise, maintenance free, improved reliability, precise peak torque transmission capability, and inherent overload protection. In this paper, a magnetic-geared PM brushless motor is presented. It is a novel low-speed and high-torque motor which merges the advantages of conventional PM brushless motor and PM gear. Its topology and operation principle are introduced. Some techniques are employed to optimize and improve the motor performance, while the validity of the proposed techniques is verified with finite-element analysis. Moreover, an alternative operation condition, which can further reduce the motor speed and increase its output torque, is proposed and analyzed.
\end{abstract}

Index Terms-Direct drive, finite-element analysis, high torque, low speed, magnetic gear, permanent-magnet (PM) motor.

\section{INTRODUCTION}

I $\mathrm{N}$ industry, about $90 \%$ of all motors have to be equipped with large gearboxes to achieve low speed and high torque. The volume and weight of the whole transmission system have been massively increased, which might result in overbudget facility investments. In addition, acoustic noise, low efficiency, low transmission precision, and slow response can also turn into considerable issues [1]. And the abrasion of the gear wheel may attenuate the system service life and reliability. Therefore, electrical drives with high torque and low speed have emerged to meet the demands from the recent development of industries.

On the other hand, magnetic gear is becoming attractive due to its significant features, such as reduced acoustic noise, maintenance-free, improved reliability, precise peak torque transmission capability, and inherent overload protection [2]. Recently, a most promising coaxial magnetic gear topology was proposed [3], Fig. 1, which has a highly competitive torque transmission capability and a very high efficiency, due to the full utility of permanent magnets (PMs). The system torque density and reliability can be significantly improved by combining a conventional PM motor with such a magnetic gear. By way of example, the motor and the gear can be combined axially (i.e., they are coupled on a same shaft). Otherwise, they can be combined radially [4] (i.e., an out-rotor PM motor is set inside a magnetic gear, while the motor outrotor is fixed with the gear high-speed rotor. However, these combined systems are more or less bulky. Therefore, a new magnetic-geared outrotor motor was proposed in the authors' early paper [5], in which a stationary armature is employed to replace the inner high-speed rotor in the magnetic gear (Fig. 2). Clearly, the rotary field generated by the armature winding currents in the motor acts as that by the high-speed rotor magnets in the magnetic gear. Such a motor artfully integrates the magnetic gear with the conventional PM brushless

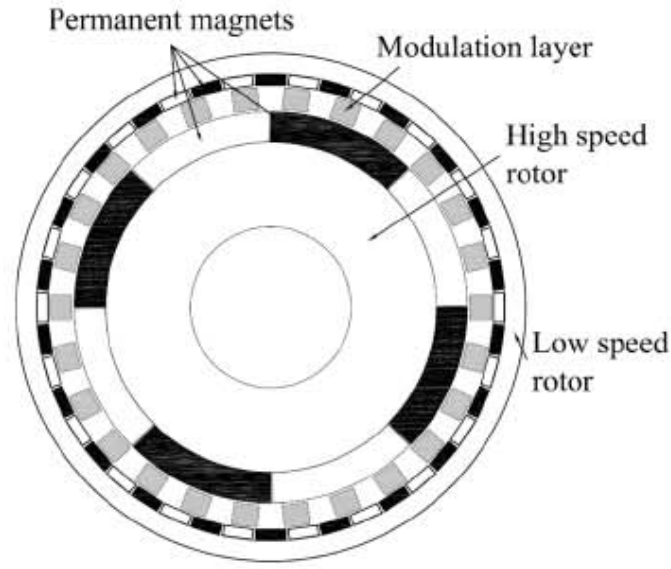

Fig. 1. Topology of magnetic gear.

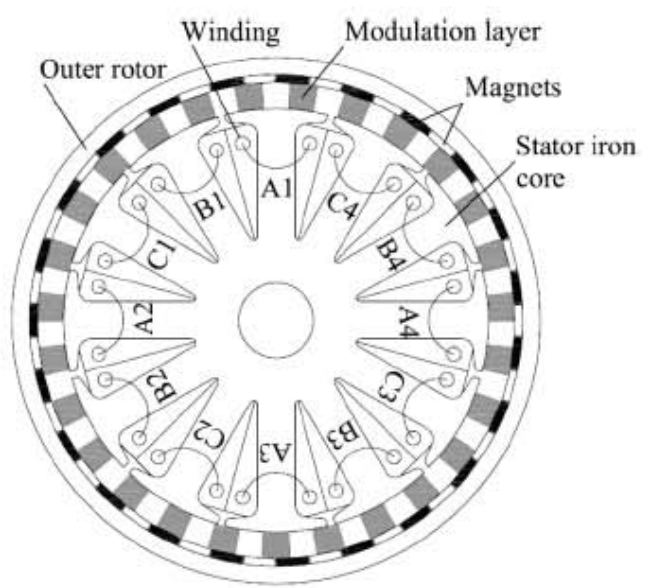

Fig. 2. Topology of magnetic-geared outer-rotor motor.

motor. It can further reduce the overall size and weight, compared with the simple radial combination of the magnetic gear and PM motor.

In this paper, some techniques are employed to optimize the motor parameters and improve the motor performance. The validity of these proposed techniques is verified with finite-element analysis (FEA). Moreover, by changing the rotating part in the proposed motor, an alternative operation condition which can further reduce the speed and increase the torque, is proposed and analyzed. The results manifest that the 
proposed motor could be a potential contender for low-speed and high-torque direct drive applications.

\section{TOPOLOGY AND OPERATION PRINCIPLE}

\section{A. Topology}

Fig. 2 shows the configuration of the proposed magneticgeared outer-rotor motor. The motor comprises an inner stator that includes stator steel laminations and armature coils, and an outer rotor that includes PMs and rotor steel laminations, which is exactly the same as that of a conventional outer-rotor PM motor. Additionally, there is a modulation layer composed of evenly distributed magnetic steel and nonmagnetic segments, which is located between the stator and outer rotor.

Consequently, an adjustment of the main parameter relations to define a poly-phased structure must be carried out and can be demonstrated as

$$
N_{s}=P_{s}+P_{r}
$$

where $P_{s}$ and $P_{r}$ are the stator magnetic pole pair number and outer-rotor magnet pair number, respectively, and $N_{s}$ is the number of magnetic steel segments in the modulation layer. The relation between the motor mechanical rotation frequency $F$ and the stator electrical frequency $f$ can be expressed as

$$
f=F \cdot P_{r} / P_{s} .
$$

For instance, Fig. 2 presents a three-phase motor with $P_{s}=$ $4, P_{r}=23, N_{s}=27$.

\section{B. Operation Principle}

The magnetic-geared out-rotor PM motor is derived from the coaxial magnetic gear which has been shown in Fig. 1. However, the high-speed rotary field is generated by the stationary armature rather than the rotating magnets.

According to [3] and [6], the following can be derived:

$$
\Omega_{r}=\frac{m P_{s}}{m P_{s}+k N_{s}} \Omega_{s}+\frac{k N_{s}}{m P_{s}+k N_{s}} \Omega_{\mathrm{ml}}
$$

where $\Omega_{r}, \Omega_{s}$, and $\Omega_{\mathrm{ml}}$ are the speed of the outer rotor, the synchronous speed of the stator armature field, and the speed of modulation layer, respectively. When the modulation layer is kept stationary (i.e., $\Omega_{\mathrm{ml}}=0$ ), the gearing ratio $N$ is given by

$$
N=\left|m P_{s}+k N_{s}\right| / m P_{s}
$$

where $m=1,3,5, \ldots, \infty$, and $k=0, \pm 1, \pm 2, \pm 3, \ldots, \infty$. In order to transmit the torque at a different rotational speed, the number of magnet pairs of the outer rotor must be equal to the number of pole pairs of a space harmonic for which $k \neq 0$. Since the combination of $m=1$ and $k=-1$ possesses the highest asynchronous space harmonic, the gear ratio can then be obtained as

$$
N=\left(P_{s}-N_{s}\right) / P_{s}
$$

A ratio of $-5.75: 1$ can be yielded for the given motor.

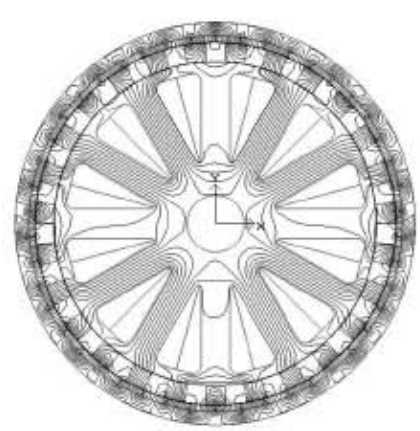

(a)

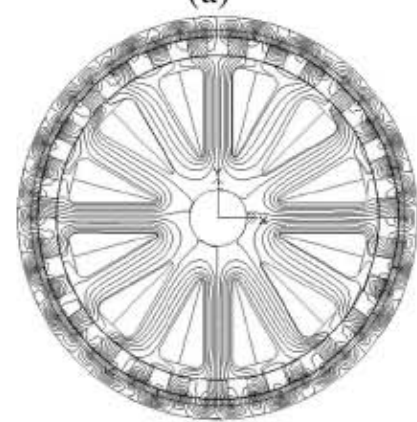

(c)

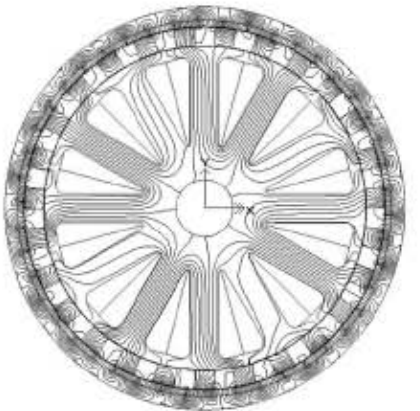

(b)

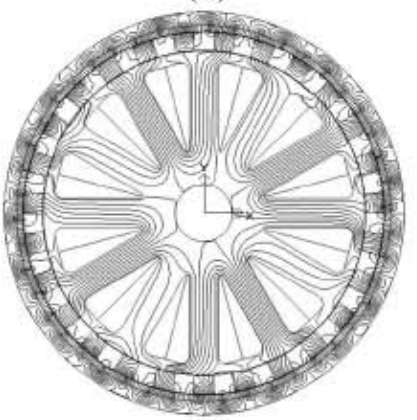

(d)
Fig. 3. Open-circuit field distributions with four rotor positions within one pole-pitch. (a) $\theta_{T}=0^{\circ}$. (b) $\theta_{T}=2^{\circ}$. (c) $\theta_{T}=4^{\circ}$. (d) $\theta_{T}=6^{\circ}$.

When the stator armature is fed with the three-phase, $50-\mathrm{Hz}$ currents, it can produce a four pole-pairs rotary field at $750 \mathrm{r} / \mathrm{min}$, just like the primary rotor of the magnetic gear with four magnet pairs at the same speed. Thus, the outer-rotor speed steps down to $130 \mathrm{r} / \mathrm{min}$ in the opposite direction. Moreover, if the stator is fed with an inverter, a variable-speed drive can be achieved, which is similar to a PM brushless drive.

Due to the function of modulating the air-gap field space harmonics, the modulation layer is the key element. The radial flux density harmonic spectra due to outer-rotor permanent magnets in the air gaps adjacent to the outer rotor and to the stator were analyzed in [5]. It was seen that, by the modulation layer, the most significant space harmonic is successfully modulated from the pole pairs in the air gap adjacent to the outer rotor to the pole pairs in the air gap adjacent to the stator.

Fig. 3 shows the simulated open-circuit flux distributions of the magnetic-geared out-rotor PM motor at four different rotor positions within one pole-pitch. $\theta_{r}=0^{\circ}$ is defined as the original rotor position of the motor. $\theta_{r}=2^{\circ}, \theta_{r}=4^{\circ}$ and $\theta_{r}=6^{\circ}$ represent the rotor moves by $1 / 4,1 / 2$, and $3 / 4$ pole-pitch, respectively. It can be noticed that the flux distribution makes a large change within a rather short pole-pitch; thus, high torque can be generated [7].

\section{Optimal Design of the Magnetic-Geared Motor}

\section{A. Modulation-Layer Optimization}

The width of the steel segments on the modulation layer as well as the angular position angle of the steel segments with the stator were analyzed in [5]. The maximum output torque can be achieved when the steel segments width is $360 / 2 N_{s} \approx 6.7^{\circ}$. It is worth mentioning that the maximum output torque keeps almost invariable when the relative position between the stator and the modulation layer changes. 


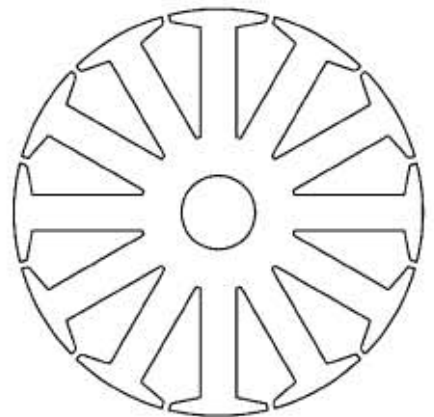

(a)

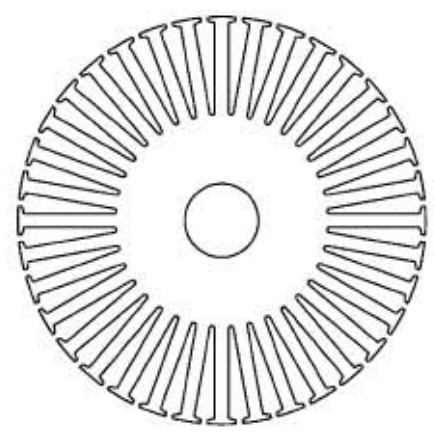

(c)

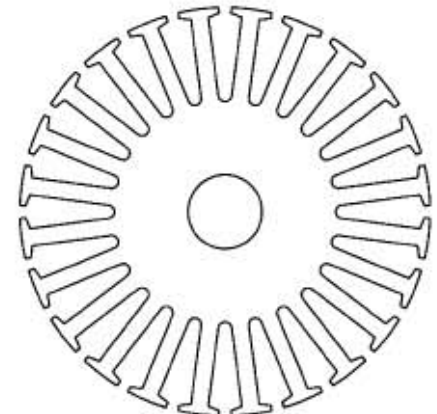

(b)

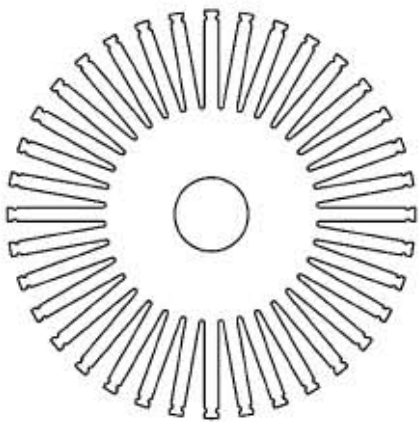

(d)
Fig. 4. Four typical stator configurations. (a) 12 stator slots. (b) 24 stator slots. (c) 36 stator slots. (d) 36 open stator slots.

\section{B. Stator Optimization}

For the stator, four typical configurations with 12-, 24-, 36-, and 36-open slots, as shown in Fig. 4, are investigated with 2-D FEA. Concentrated windings are employed for the 12-slot motor to achieve $P_{s}=4$, while conventional distributed windings are used for 24- and 36-slot motors to obtain the same $P_{s}$. In order to carry out the comparisons of the different designs, the same stator dimension, same number of winding turns per coil, and the same winding package factor are presumed. Furthermore, the same modulation layer and same rotor with sintered $\mathrm{NdFeB}$ magnets are used. Fig. 5 shows the back electromotive force (emf) profiles with the four typical stator configurations. It can be seen that the no-load back-emf waveforms induced by PMs in the phase windings are nearly sinusoidal for all of the configurations, which implies that the presented motors are congenitally suitable for sine-wave operation. The frequency of the phase-back emfs can be found out to be the same as $50 \mathrm{~Hz}$ when the outer rotors operate at the rated speed $(130 \mathrm{r} / \mathrm{min})$, which agrees with the operation principle. Moreover, Fig. 5 demonstrates that the back-emf amplitudes of type (c) and (d) are close, but are nearly three times larger than those of type (a) and (b), which can be explained as the extensive improvements of the winding utilizations.

Furthermore, the output torque waveforms with the four typical stator configurations are presented in Fig. 6, where sinewave currents in the same phase of back-emfs are fed into the windings. Although the distributed windings of types (b)-(d) normally accompany with relatively longer end windings and possibly slightly lower winding package factors, which might negatively affect the motor performances, the superior torque capability of types (b)-(d) under the condition of the same current density and the same number of winding turns per coil

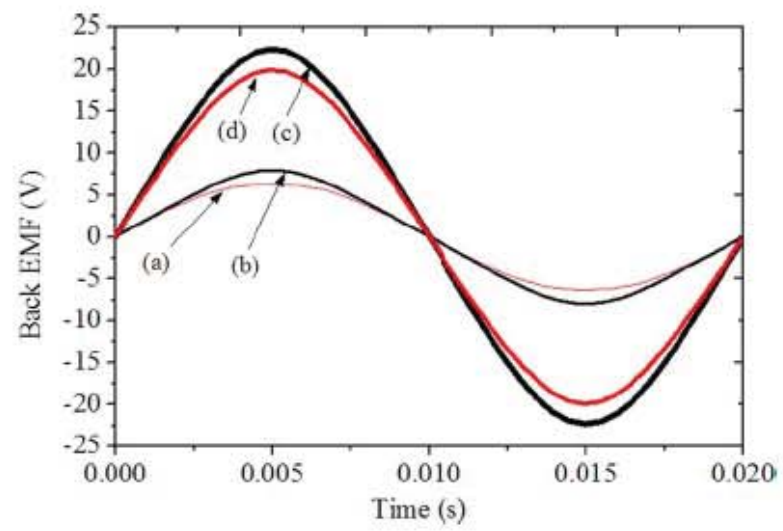

Fig. 5. Back-emf waveforms with the four typical stator configurations.

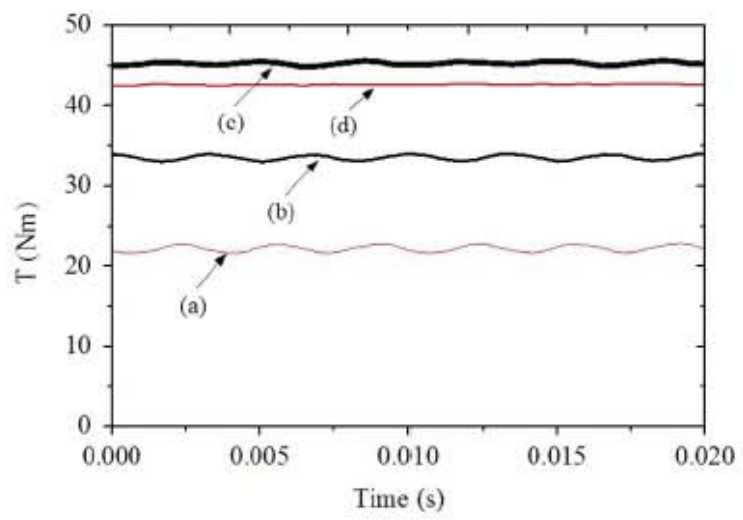

Fig. 6. Output torque with the four typical stator configurations.

TABLE I

MOTOR PARAMETERS

\begin{tabular}{clcc}
\hline \hline \multirow{2}{*}{ Symbol } & \multicolumn{1}{c}{ Motor Parameter } & Value & Unit \\
& & & \\
\hline$N_{\text {coil }}$ & Number of winding turns per coil & 30 & \\
$K_{p}$ & Winding package factor & $70 \%$ & \\
$R_{s i}$ & Stator inner radius & 16 & $\mathrm{~mm}$ \\
$R_{s o}$ & Stator outer radius & 88.5 & $\mathrm{~mm}$ \\
$R_{m i}$ & Modulation layer inner radius & 89 & $\mathrm{~mm}$ \\
$R_{m o}$ & Modulation layer outer radius & 99 & $\mathrm{~mm}$ \\
$R_{r i}$ & Rotor inner radius & 99.5 & $\mathrm{~mm}$ \\
$R_{r i}$ & Rotor outer radius & 110 & $\mathrm{~mm}$ \\
$h_{p m}$ & Permanent magnet thickness & 3 & $\mathrm{~mm}$ \\
$k_{p m}$ & Permanent magnet width & 8 & degree \\
$k_{m l}$ & Steel segment width & 6.7 & degree \\
$l$ & Motor active axial length & 21 & $\mathrm{~mm}$ \\
$J$ & Rated current density & 6.5 & $\mathrm{~A} / \mathrm{mm}^{2}$ \\
$f$ & Rated frequency & 50 & $\mathrm{~Hz}$ \\
$n$ & Rated speed & 130 & $\mathrm{rpm}$ \\
\hline \hline
\end{tabular}

would fully compensate the impacts. Consequently, types (c) and (d) can enjoy a rather higher torque output. Fig. 6 also indicates that the torque ripples are evidently suppressed as the output torque rises, especially in the case of type (d).

The key parameters of the proposed motor are all included in Table I. Moreover, Table II lists the specific motor performance with different stator types when the motor runs at $130 \mathrm{r} / \mathrm{min}$. Though types (b)-(d) have lower efficiency than type (a) due to the additional winding resistance from the longer end windings, they can supply more output torque and, thus, are still acceptable. 
TABLE II

MOTOR PERFORMANCE WITH DIFFERENT STATOR TYPES

\begin{tabular}{ccc}
\hline \hline Stator type & Output torque & Efficiency \\
\hline (a) & $22.2 \mathrm{Nm}$ & $81.1 \%$ \\
(b) & $33.5 \mathrm{Nm}$ & $78.6 \%$ \\
(c) & $45.3 \mathrm{Nm}$ & $74.2 \%$ \\
(d) & $42.7 \mathrm{Nm}$ & $77.3 \%$ \\
\hline \hline
\end{tabular}

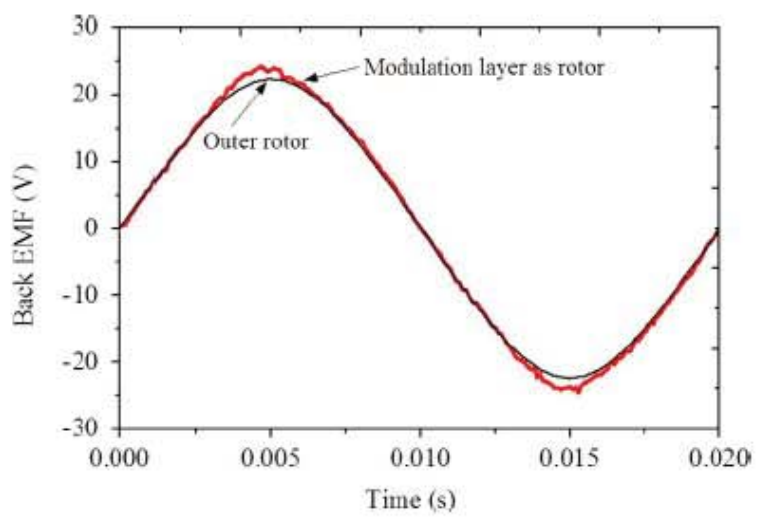

Fig. 7. Back-emf waveforms with different rotors.

\section{Alternative Operation CONDITION}

\section{A. Operation Principle}

According to [6], if the outer rotor is held stationary (i.e., $\Omega_{r}=0$ ), while the modulation layer rotates, then the gearing ratio $N$ is given by

$$
N=-k N_{s} / m P_{s}
$$

The combination of $m=1$ and $k=-1$, as well as $P_{s}=4$ and $N_{s}=27$ are chosen; thus, the gear ratio would be 6.75:1. Similarly, when the stator armature is fed with the three-phase, 50-Hz sine-wave currents, it can deliver a four-pole-pairs rotary field at $750 \mathrm{r} / \mathrm{min}$, hence, the modulation layer speed steps down to $111 \mathrm{r} / \mathrm{min}$ in the same direction.

\section{B. Performance Analysis}

Fig. 7 shows the comparison of the back-emf waveforms with different rotors. The back-emf profiles are obtained under the same electrical frequency for both modes, namely, the speed of outer rotor is $130 \mathrm{r} / \mathrm{min}$, while the speed of the modulation layer is $111 \mathrm{r} / \mathrm{min}$ at a reversal direction. It can be observed that the back-emf waveforms are almost the same. Apparently, it agrees with the operation principle. According to the operation principle, when the stator windings are fed with the same current in the two operation modes, the rotor speed steps down 1.17 times further in the alternative mode, and the output torque increases by 1.17 times. The output torque of the alternative modes is evaluated (Fig. 8), which verifies the analyzed results. As can be expected, in the alternative mode, the position between the magnetic steels in the modulation layer and stator slots is no longer fixed, the nonlinearity of the magnetic circuit will emerge

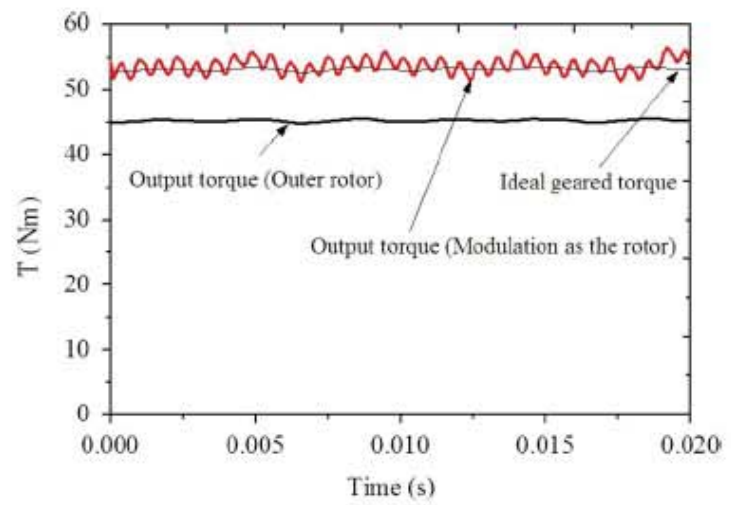

Fig. 8. Output torque with different rotors.

more often when the modulation layer is rotating, due to the fringing effects in the slots of modulation layer and stator. Consequently, the modulation-layer output torque suffers from high torque ripple, as shown in Fig. 8. The figure also shows that the ideal geared torque, which is calculated from the outer-rotor output torque divided by 1.17 , is just the average value of the modulation-layer output torque. Therefore, the output torque of $55 \mathrm{Nm}$ can be achieved by employing the alternative operation mode.

\section{CONCLUSION}

In this paper, the topology and operation principle of the magnetic-geared out-rotor PM motor are briefly introduced, and the stator structure optimization is employed to improve the motor performance. Furthermore, the alternative operation condition with the modulation layer rotating, which can further reduce the rotor speed and increase the output torque, is proposed and analyzed. It is concluded that the proposed motor possesses distinct advantages that underpin the motor as a potential candidate for low-speed and high-toque direct drive applications. The aforementioned issues have been verified with FEA results, while prototypes will be made for experimental verifications.

\section{REFERENCES}

[1] H. M. Li and Q. F. Li, Electromagnetic-Speed-Reduction Electric Motors. Beijing, China: Mechanical Industry Press, 1982.

[2] K. Ikuta, S. Makita, and S. Arimoto, "Non-contact magnetic gear for micro transmission mechanism," in Proc. IEEE Conf. Micro Electro Mechanical Systems, Nara, Japan, 1991, pp. 125-130.

[3] K. Atallah and D. Howe, "A novel high performance magnetic gear," IEEE Trans. Magn., vol. 37, no. 4, pp. 2844-2846, Jul. 2001.

[4] K. T. Chau, D. Zhang, J. Z. Jiang, C. Liu, and Y. J. Zhang, "Design of a magnetic-geared outer-rotor permanent-magnet brushless motor for electric vehicles," IEEE Trans. Magn., vol. 43, no. 6, pp. 2504-2506, Jun. 2007.

[5] L. L. Wang, J. X. Shen, Y. Wang, and K. Wang, "A novel magneticgeared outer-rotor permanent-magnet brushless motor," in Proc. Inst. Eng. Technol. Power Electron. Machines Drives, York, U.K., 2008, pp. 33-36.

[6] K. Atallah, S. D. Calverley, and D. Howe, "Design, analysis and realization of a high-performance magnetic gear," Proc. Inst. Elect. Eng., Electr. Power Appl., vol. 151, pp. 135-143, Mar. 2004.

[7] A. Toba and T. A. Lipo, "Novel dual-excitation permanent magnet vernier machine," in Proc. IEEE Conf. Rec. Ind. Appl. Soc. Annu. Meeting, 1999, pp. 2539-2544. 